Article

\title{
Analysis of Growth Inhibition and Metabolism of Hydroxycinnamic Acids by Brewing and Spoilage Strains of Brettanomyces Yeast
}

\section{Michael Lentz * and Chad Harris}

Department of Biological Sciences, University of North Florida, Jacksonville, FL 32224, USA;

E-Mail: chadlharris@hotmail.com

* Author to whom correspondence should be addressed; E-Mail: mlentz@unf.edu;

Tel.: +1-904-620-1064.

Academic Editor: Felix Barron

Received: 29 July 2015 / Accepted: 10 October 2015 / Published: 15 October 2015

\begin{abstract}
Brettanomyces yeasts are well-known as spoilage organisms in both the wine and beer industries, but also contribute important desirable characters to certain beer styles. These properties are mediated in large part by Brettanomyces' metabolism of hydroxycinnamic acids (HCAs) present in beverage raw materials. Here we compare growth inhibition by, and metabolism of, HCAs among commercial brewing strains and spoilage strains of $B$. bruxellensis and $B$. anomalus. These properties vary widely among the different strains tested and between the HCAs analyzed. Brewing strains showed more efficient metabolism of ferulic acid over $p$-coumaric acid, a trait not shared among the spoilage strains.
\end{abstract}

Keywords: Brettanomyces; hydroxycinnamic acid; fermentation; phenolic acid

\section{Introduction}

Brettanomyces yeast are ubiquitous around the world and are commonly encountered in commercial fermentation settings. They are well-known for their ability to metabolize organic compounds common in wine must and beer wort into low-threshold volatile products that greatly affect the organoleptic qualities of the finished product. There are presently five species recognized within the genus Brettanomyces: B. bruxellensis, B. anomalus, B. nanus, B. naardenensis, and B. custersianus. 
Teleomorph (spore-forming) forms have been reported for B. bruxellensis and B. anomalus and are identified as the Dekkera genus [1]; these forms are rare and Brettanomyces will be used in this manuscript.

Brettanomyces is probably best known as a contributor to wine spoilage. The yeasts are distributed worldwide, and may arrive at a winery on fruit skins, or reside on winery surfaces or barrels [2-6]. Once present in a winery, they are difficult to eradicate. Brettanomyces are slow growing, and do not compete well with Saccharomyces yeast during active fermentation. Since they are tolerant of low $\mathrm{pH}$ and high alcohol, and can metabolize sugars and other organic molecules left behind by Saccharomyces, they may gain a foothold in a wine near the end of fermentation or during aging [2,7]. If they are allowed to persist, the wine may develop "Brett taint", a characteristic set of off-flavors and aromas often described as rubber, burnt plastic, medicinal, leathery, goaty, barnyard, etc. Brettanomyces' full metabolic contribution to wine flavor and aroma is poorly understood, however the characteristics described above are primarily attributed to these yeasts' ability to metabolize hydroxycinnamic acids (HCAs) [8,9].

HCAs are a family of small phenolic acids found in all plant cells. They contribute to plant cell wall structure by forming cross-links between hemicellulose and lignin in the secondary cell wall [10,11]. Free HCAs are present in addition to crosslinks. Common HCAs include ferulic acid, $p$-coumaric acid, caffeic acid, and sinapic acid. They are present in varying proportions in different plant and cell types [12,13]. During maceration and vinification of grapes or malting and mashing of barley, HCAs are released from cells, and are always present in must and wort $[14,15]$. In addition to their role in plant cell wall structure, HCAs may also function as antimicrobial compounds in the plant, although the mechanisms are poorly characterized [11,16-18]. A variety of bacteria and fungi have evolved pathways to metabolize HCAs to less toxic products. In most of these organisms, HCAs are converted to vinyl derivatives through a phenolic acid decarboxylase (PAD) enzyme [19,20]. The specific vinyl compound depends on the HCA substrate, but all have very low flavor and aroma thresholds, and play a major role in wine spoilage. Some organisms, including Brettanomyces, encode a vinyl reductase (VR) enzyme that converts the vinyl compounds to ethyl derivatives, further contributing to off-flavors and aromas [21].

While Brettanomyces is nearly universally considered a flaw in wine, there are several styles of beer where Brettanomyces' contribution is desired and even required. These styles include Lambics, gueuze, Flanders Red and Brown ales, and a growing list of American "wild" ales, whose popularity is rapidly increasing [22]. Some of the desired descriptors overlap with those in wine, including barnyard and leather. Other characteristics attributed to Brettanomyces include spicy, clove, and smoky $[1,23]$. The compounds that contribute to these beer qualities are also attributed to metabolism of HCAs by PAD and VR enzymes. The factors that determine the final qualities of the beer or wine are complex, and will depend on the type and relative concentration of HCA precursors, the timing of Brettanomyces introduction and relative proportion of Brettanomyces to other yeasts, and Brettanomyces strain variation [1,23]. B. bruxellensis is the dominant species associated with wine spoilage, while both B. bruxellensis and B. anomalus contribute to beer varieties [24,25]. Here we have investigated Brettanomyces strain variation for growth in and metabolism of different HCAs in order to better understand the complex contribution of Brettanomyces to commercial fermented beverages. The properties tested varied widely among the different strains analyzed and between three HCAs. Brewing strains of both species showed more efficient metabolism of ferulic acid over $p$-coumaric acid, a trait unique to these strains. 


\section{Experimental Section}

\subsection{Strains}

All strains used were either Brettanomyces bruxellensis or B. anomalus. Eight strains were isolated from environmental sources. Strains 1-4, 6, and 7 were previously described isolates from ripe fruit [26]. Strains 5 and 8 are new isolates from Florida seagrape (Coccoloba uvifera) and blueberry (Vaccinium sp.), respectively. The remaining strains are commercially available for professional brewing and were obtained by purchase. All analyses started with single colony isolates. Commercial strains are deemed suitable for brewing as advertised. The environmental isolates were used to brew pilot batches and judged by experienced tasters [26]. Strain 6 has been used routinely by a microbrewery for $100 \%$ Brettanomyces fermentations. Brewing suitability is defined here as a yeast strain used as the sole fermenter of beer wort without detectable undesirable phenolic off-flavors or aromas. Strain information is shown in Table 1.

Table 1. Strain designation, source and suitability for brewing.

\begin{tabular}{cccc}
\hline Strain & Species & \multicolumn{1}{c}{ Source * } & Brewing Suitability \\
\hline 1 & B. bruxellensis & Environmental (Bc02) & No \\
2 & B. bruxellensis & Environmental (Bc07) & No \\
3 & B. bruxellensis & Environmental (Bc11) & No \\
4 & B. anomalus & Environmental (Cs01) & Yes \\
5 & B. anomalus & Environmental (Cu02) & Yes \\
6 & B. anomalus & Environmental (Ej02) & Yes \\
7 & B. anomalus & Environmental (Rs01) & Yes \\
8 & B. anomalus & Environmental (Vc01) & No \\
9 & B. anomalus & Commercial (WLP645) & Yes \\
10 & B. bruxellensis & Commercial (WLP650) & Yes \\
11 & B. bruxellensis & Commercial (WLP653) & Yes \\
12 & B. anomalus & Commercial (WY5151) & Yes \\
\hline * WLP, White Labs Inc. (San Diego, CA, USA); WY, Wyeast Laboratories, Inc. (Odell, OR, USA).
\end{tabular}

\subsection{Minimum Inhibitory Concentration}

MYPG culture medium (3 g malt extract, 3 g yeast extract, $2 \mathrm{~g}$ Peptone, $10 \mathrm{~g}$ glucose per liter) was prepared containing zero through $20 \mathrm{mM}$ ferulic acid, p-coumaric acid, or caffeic acid, in $2 \mathrm{mM}$ increments. Caffeic acid and $p$-coumaric acid were also analyzed at 25,30, and $35 \mathrm{mM}$ concentrations. $200 \mu \mathrm{L}$ aliquots were added to the wells of a sterile 96-well microtiter plate. The top two rows of eight columns contained zero $\mathrm{mM}$, with increasing concentrations down the remaining wells in the column. $2 \mu \mathrm{L}$ of actively growing yeast culture was added to rows $2-12$, with each strain cultured in duplicate. The top row remained uninoculated (negative control). Plates were placed in ziploc bags with damp paper towels to prevent drying, and incubated at $26{ }^{\circ} \mathrm{C}$ for $72 \mathrm{~h}$. Minimum inhibitory concentration (MIC) was defined as the lowest concentration of HCA in which no visible growth was observed. 


\subsection{Growth Characteristics in HCAs}

MYPG culture medium was prepared with or without (control) $4 \mathrm{mM}$ ferulic acid, $p$-coumaric acid, or caffeic acid. $15 \mathrm{~mL}$ samples were inoculated with cells to a concentration of $10^{5}$ cells $/ \mathrm{mL}$. Each strain was cultured in duplicate for each HCA and control culture. Cultures were grown at $24{ }^{\circ} \mathrm{C}$ on a shaker platform at $60 \mathrm{rpm}$. At regular time intervals over 14 days, $200 \mu \mathrm{L}$ samples were removed and growth was measured by determining optical density at $600 \mathrm{~nm}$. Each culture was sampled in duplicate at each time point.

\subsection{Spectral Scan Peak Absorbance}

MYPG was supplemented with $2 \mathrm{mM}$ ferulic, $p$-coumaric, or caffeic acid. $20 \mu \mathrm{L}$ of each prepared culture medium was diluted into $180 \mu \mathrm{L} \mathrm{H}_{2} \mathrm{O}$. A spectral scan from 200-400 nm was performed on a BioTek PowerWave XS plate reader to determine peak absorbance wavelength and the absorbance value at the peak wavelength. This data was recorded for use in calculating HCA metabolism as described below. Peak absorbance corresponded linearly with HCA concentration (data not shown).

\subsection{Metabolism of HCAs}

MYPG was supplemented with $2 \mathrm{mM}$ ferulic, $p$-coumaric, or caffeic acid. $200 \mu \mathrm{L}$ of each MYPG/HCA preparation was added to wells of a 96-well microtiter plate. Two microliters of active 2-3 day culture of each yeast strain was added to a well; each strain in triplicate for each HCA. Plates were kept in a humidified ziplock bag and incubated at $26^{\circ} \mathrm{C}$ for 14 days. After 14 days growth, samples were transferred to microtubes and cells were removed by centrifugation. $20 \mu \mathrm{L}$ of culture supernatant was diluted into $180 \mu \mathrm{L} \mathrm{H} \mathrm{H}_{2} \mathrm{O}$ and the absorbance value at the peak wavelength was determined as described above for each HCA (313 nm for ferulic acid and caffeic acid; $287 \mathrm{~nm}$ for $p$-coumaric acid). The value for each sample was divided by the OD of the original sample, and the average determined for each strain, as well as the standard deviation from the mean. Results are reported as the concentration of HCA that remained in the sample after the 14 day incubation.

\section{Results}

\subsection{Minimum Inhibitory Concentration}

The MIC for each strain was tested in ferulic acid, $p$-coumaric acid, and caffeic acid from 0-20 mM. All strains grew well in media supplemented with caffeic acid at $20 \mathrm{mM}$, exhibiting no inhibition by this compound. Strains 1,2, and 7-11 also grew at $20 \mathrm{mM} p$-coumaric acid. These strains represent both $B$. bruxellensis and $B$. anomalus, and brewing and non-brewing strains of each species. All strains were retested in 25, 30, and $35 \mathrm{mM} p$-coumaric and caffeic acid. All strains that grew in $20 \mathrm{mM} p$-coumaric acid were inhibited by $25 \mathrm{mM}$, and all strains were inhibited by $25 \mathrm{mM}$ caffeic acid except 7 and 11, which required $30 \mathrm{mM}$ for inhibition. Strains 3, 4, 5, 6, and 12 were unable to grow in $p$-coumaric acid concentrations of $10 \mathrm{mM}, 12 \mathrm{mM}, 8 \mathrm{mM}, 14 \mathrm{mM}$, and $8 \mathrm{mM}$, respectively. Strain 3 is B. bruxellensis, while the rest are B. anomalus. Ferulic acid provided the strongest inhibition, with one strain (\#4) growing in $14 \mathrm{mM}$, but no others growing at concentrations above $12 \mathrm{mM}$. Inhibition of growth above 
$6 \mathrm{mM}$ was observed for three of the strains (3,5 and 12). Growth at $12 \mathrm{mM}$ but not above this concentration was seen for strains $6,7,9,10$ and 11 , all strains that have been used successfully in pilot or commercial brewing. The remaining strains were inhibited by intermediate concentrations of ferulic acid (Table 2).

Table 2. Minimum inhibitory concentrations (millimolar) of hydroxycinnamic acids (HCAs) for each strain.

\begin{tabular}{ccccccccccccc}
\hline \multirow{2}{*}{ HCA } & $\mathbf{1 0}$ & $\mathbf{1}$ & $\mathbf{3}$ & $\mathbf{4}$ & $\mathbf{5}$ & $\mathbf{6}$ & $\mathbf{7}$ & $\mathbf{8}$ & $\mathbf{9}$ & $\mathbf{1 0}$ & $\mathbf{1 1}$ & $\mathbf{1 2}$ \\
\cline { 2 - 13 } & 10 & 10 & 8 & 14 & 8 & 12 & 12 & 16 & 12 & 12 & 12 & 8 \\
ferulic acid & 25 & 25 & 10 & 12 & 8 & 14 & 25 & 25 & 25 & 25 & 25 & 8 \\
$p$-coumaric acid & 25 & 25 & 25 & \\
caffeic acid & 25 & 25 & 25 & 25 & 25 & 25 & 30 & 25 & 25 & 25 & 30 & 25 \\
\hline
\end{tabular}

\subsection{Growth Properties}

We next determined what effect exposure to HCAs had on growth properties of Brettanomyces isolates. Cells were grown in the presence or absence of $4 \mathrm{mM} \mathrm{HCA}$, and growth monitored by absorbance at $600 \mathrm{~nm}$. There was no growth difference at any time point between control samples and cells grown in $4 \mathrm{mM}$ caffeic acid, except for strain 11, which plateaued at a slightly lower density than control cells (Figure 1). In contrast, most strains were significantly impaired for growth in $4 \mathrm{mM}$ ferulic acid and $4 \mathrm{mM} p$-coumaric acid. Some strains showed a growth lag at early time points, then caught up to the control cultures. Others showed a lag, but remained at lower cell densities throughout the growth period. Two isolates of B. bruxellensis and two of B. anomalus did not show any growth inhibition with any of the HCAs tested. Of those that were inhibited by ferulic and $p$-coumaric acid, all but two isolates were inhibited to the same extent by both acids, while two were inhibited to a significantly greater extent by ferulic acid than $p$-coumaric acid. Growth properties are summarized in Table 3.

\subsection{Metabolism of HCAs}

We next determined the relative metabolic activity of each strain for different HCAs. As can be seen in Figure 2, there is wide variation among isolates for metabolism of the different substrates. Some common themes were also observed. All 12 strains utilized caffeic acid least efficiently of the three HCAs tested, ranging from not using this substrate at all, to reducing the caffeic acid concentration by about 50 percent. Ferulic acid and $p$-coumaric acid were metabolized equally efficiently by five of the strains, however the HCA concentration remaining after metabolism ranged from $0.1 \mathrm{mM}$ to approximately $1 \mathrm{mM}$ (from a starting concentration of $2 \mathrm{mM}$ ) within this group. Six strains metabolized ferulic acid more efficiently than $p$-coumaric acid, again with wide strain-to-strain variation. Only one strain utilized $p$-coumaric acid more efficiently than ferulic acid. These results are further summarized in Table 3. 


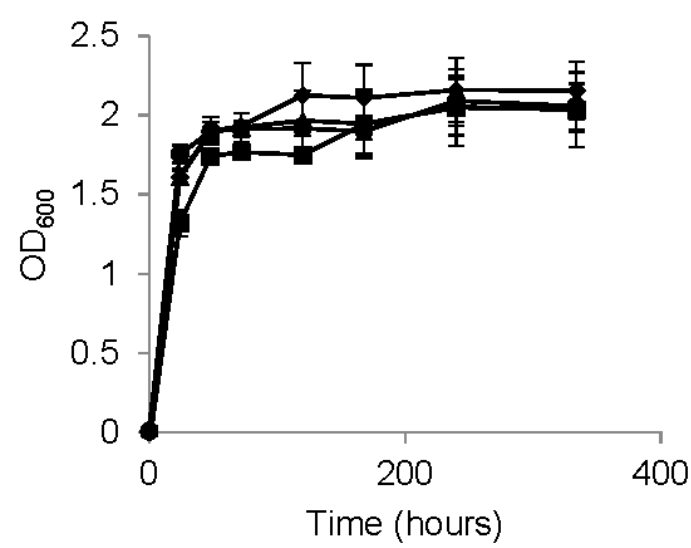

Strain 1

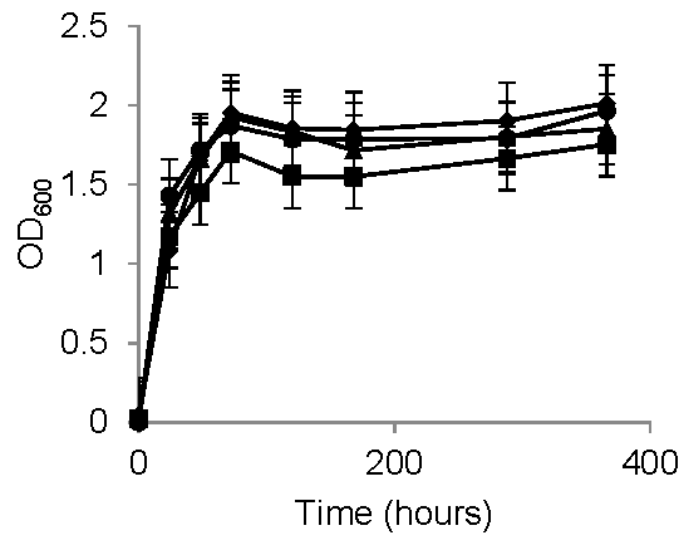

Strain 3

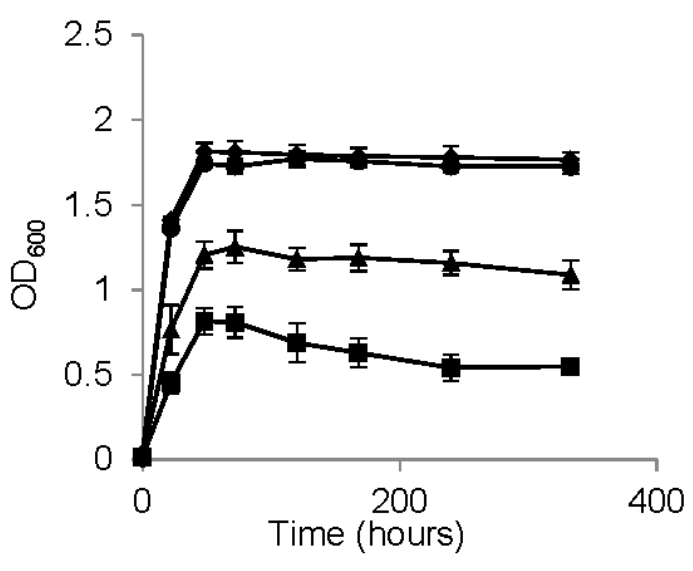

Strain 5

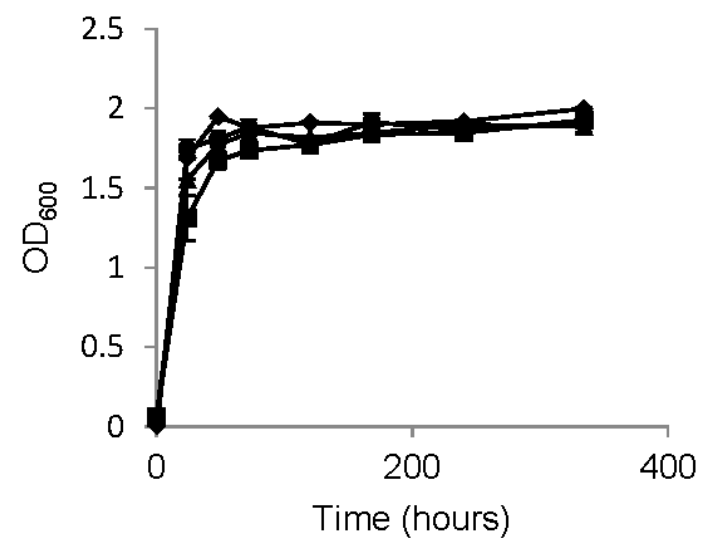

Strain 2

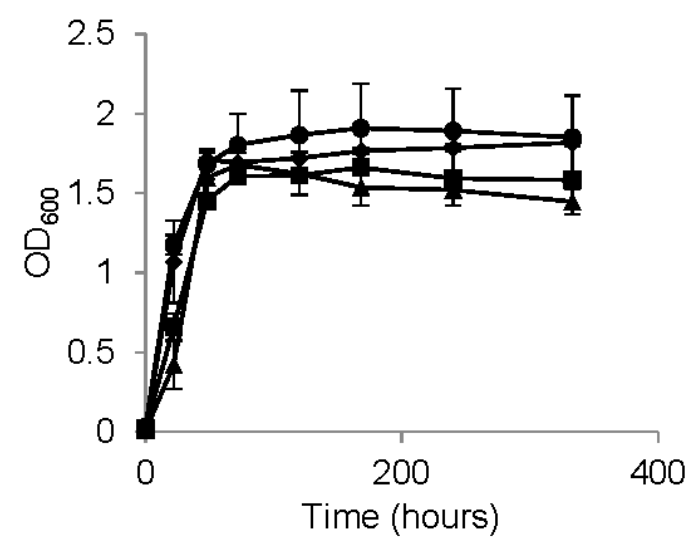

Strain 4

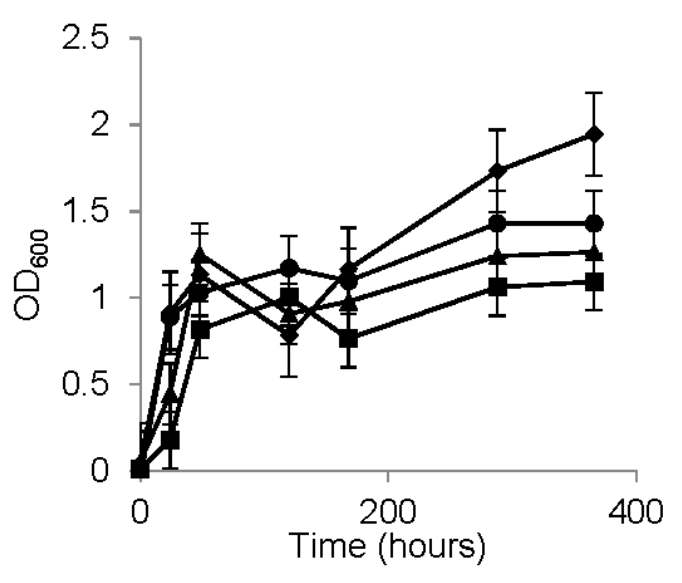

Strain 6

Figure 1. Cont. 

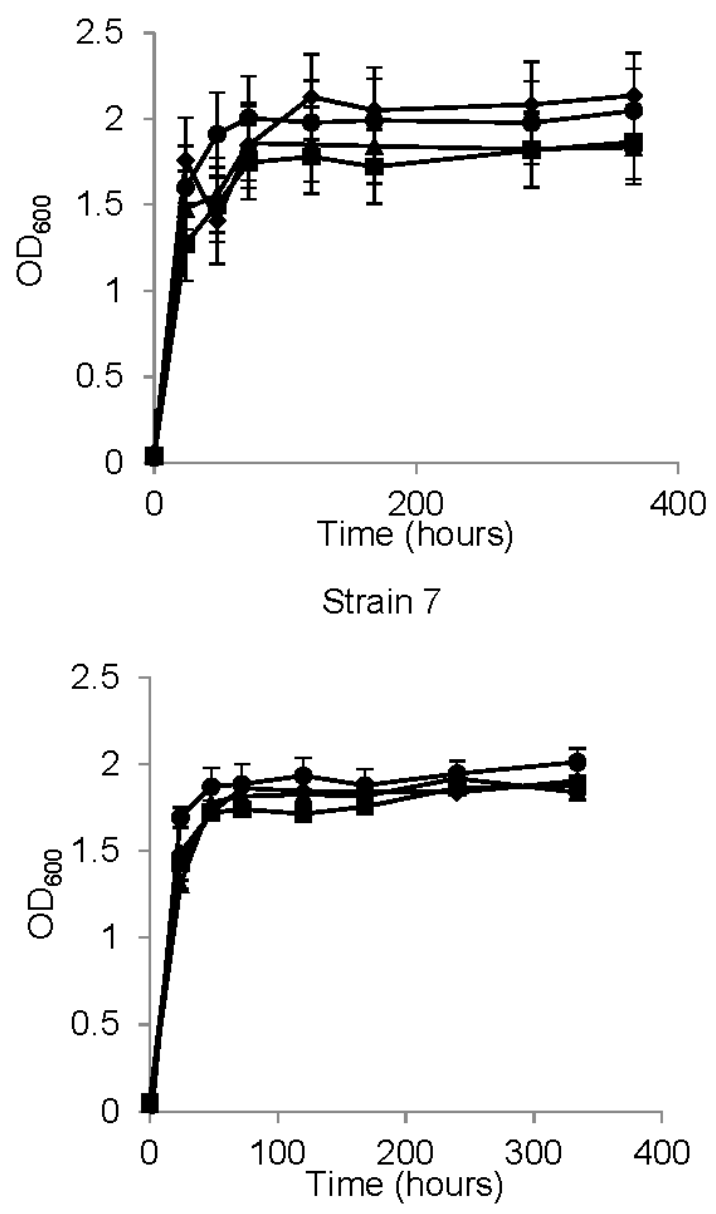

Strain 9

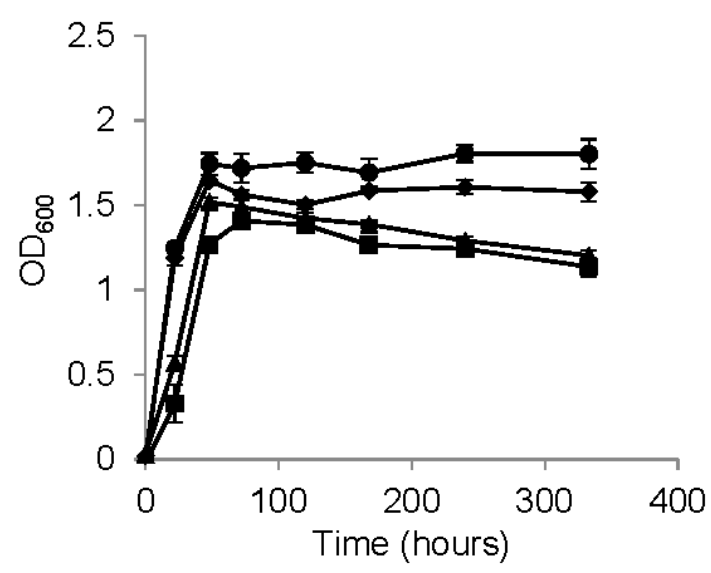

Strain 11

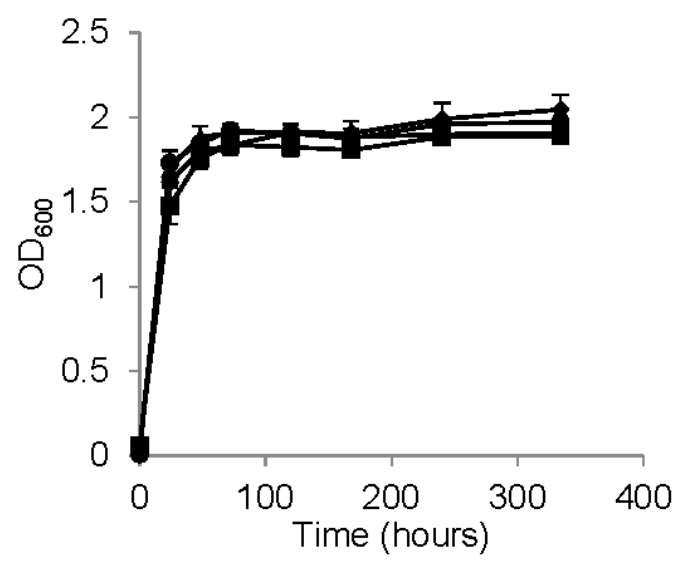

Strain 8
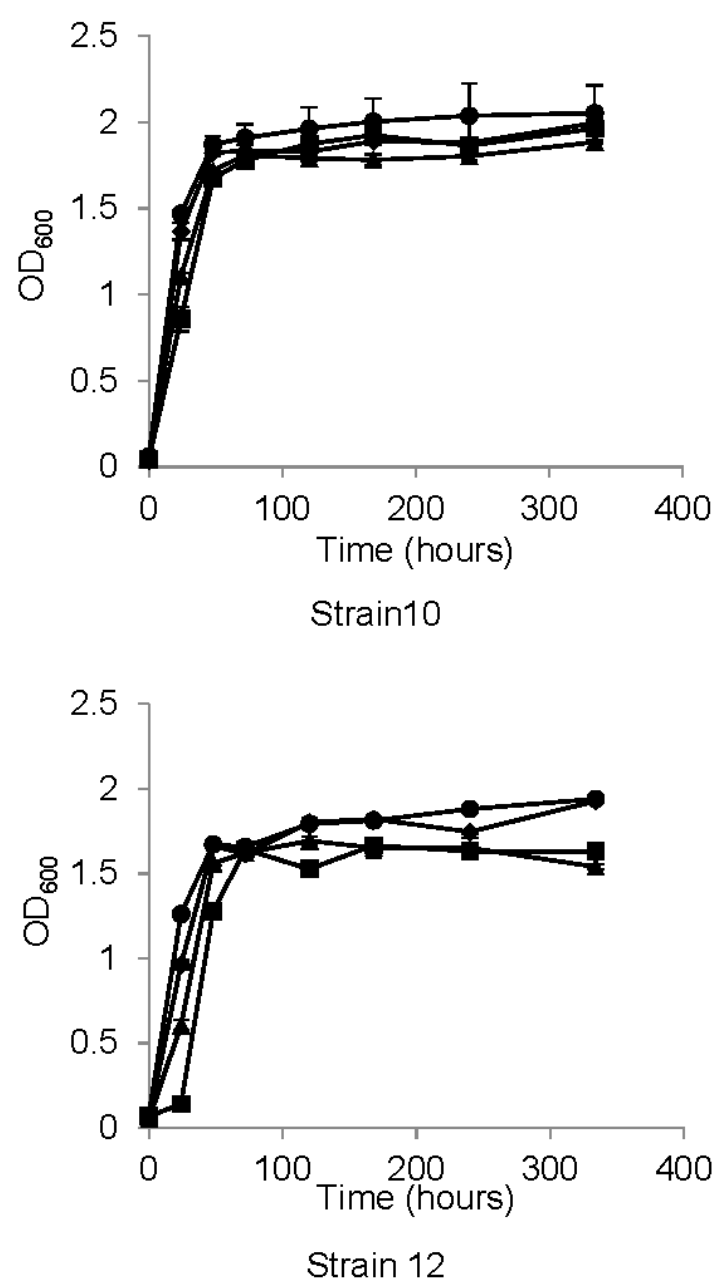

Figure 1. Growth curves for each strain in the presence or absence of added hydroxycinnamic acid (HCA). MYPG culture medium was supplemented with 4 mM HCA and growth measured by optical density at the indicated time points. Circles, control (no HCA); squares, ferulic acid; triangles, $p$-coumaric acid; diamonds, caffeic acid. Bars represent standard error of the mean. 
Table 3. Correlation of strain properties with brewing potential.

\begin{tabular}{|c|c|c|c|c|c|c|c|}
\hline \multirow{2}{*}{ Strain } & \multicolumn{3}{|c|}{ Greater inhibition by* } & \multicolumn{3}{|c|}{ Metabolism of HCAs* } & \multirow{2}{*}{$\begin{array}{c}\text { Suitability } \\
\text { For Brewing }\end{array}$} \\
\hline & FA & $p C A$ & Same & $\mathbf{F A}>p \mathbf{C A}$ & $p C A>F A$ & $\mathbf{F A}=p \mathbf{C A}$ & \\
\hline 1 & $\mathrm{X}$ & & & & & $\mathrm{X}$ & No \\
\hline 2 & $\mathrm{X}$ & & & & & $X$ & No \\
\hline 3 & $\mathrm{X}$ & & & & & $\mathrm{X}$ & No \\
\hline 4 & & $\mathrm{X}$ & & & & $X$ & Yes \\
\hline 5 & & & $\mathrm{X}$ & $\mathbf{v}$ & & & Yes \\
\hline 6 & $\mathrm{X}$ & & & $\mathbf{x}$ & & & Yes \\
\hline 7 & $\mathrm{X}$ & & & & $\mathrm{X}$ & & $\overline{\text { Yes }}$ \\
\hline 8 & $\mathrm{X}$ & & & & & $\mathrm{X}$ & No \\
\hline 9 & $\mathrm{X}$ & & & $\mathrm{X}$ & & & Yes \\
\hline 10 & $\mathrm{X}$ & & & 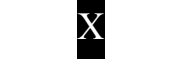 & & & Yes \\
\hline 11 & $\mathrm{X}$ & & & $x$ & & & Yes \\
\hline 12 & & & $\mathrm{X}$ & $\mathrm{X}$ & & & Yes \\
\hline
\end{tabular}

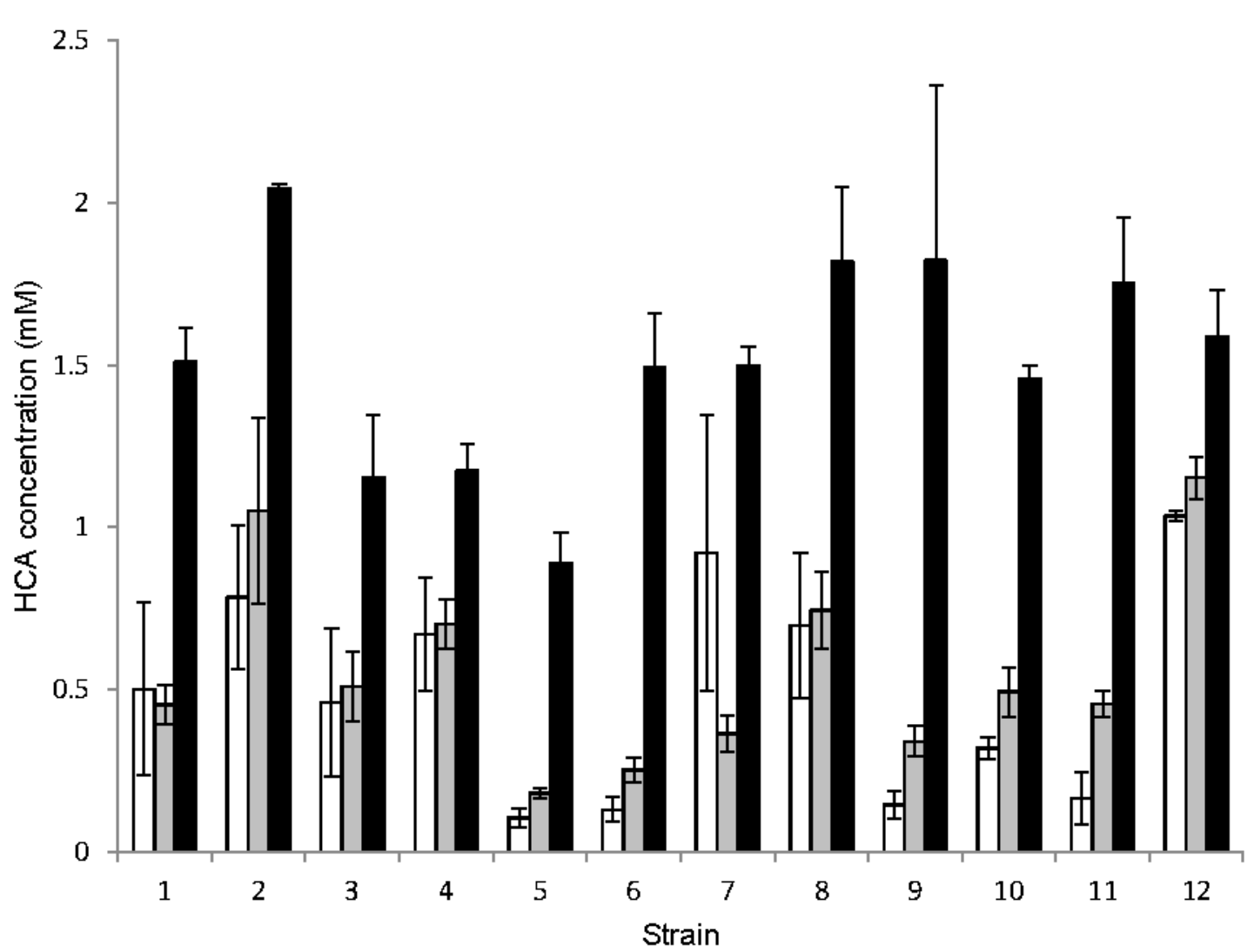

Figure 2. Metabolism of hydroxycinnamic acids (HCA) by yeast strains. Strains were incubated in MYPG supplemented with $2 \mathrm{mM} \mathrm{HCA}$. The concentration of HCA remaining after 14 days was determined by measuring the absorbance at $313 \mathrm{~nm}$ (ferulic acid and caffeic acid) or $287 \mathrm{~nm}$ ( $p$-coumaric acid) compared to the absorbance of a sample incubated without added cells. White bars, ferulic acid; gray bars, $p$-coumaric acid; black bars, caffeic acid. Graph represents mean plus standard error of the mean. 


\section{Discussion}

We have investigated variation among species and strain isolates of Brettanomyces yeast for metabolism of phenolic acids that naturally occur in beer wort and wine must. Isolates included commercial brewing strains and local environmental isolates. We aim to determine the role of strain variation in observed differences for production of volatile phenols in finished beer or wine. These compounds play an important role in wine spoilage, yet also contribute to unique, desired characteristics of certain beer styles.

Caffeic acid was the weakest inhibitor of the HCAs tested. This observation is in general agreement with published data for other strains that show weak or no inhibition of growth by this compound compared to other cinnamic acids [16]. Strains exhibited wide variability for inhibition by ferulic acid and $p$-coumaric acid. When a strain showed variation for inhibition by these two HCAs, ferulic acid was always a more potent inhibitor, with the sole exception of strain 4 . This data supports results from similar experiments using different strains of B. bruxellensis and B. anomalus [27]. It appears that Brettanomyces in general are only weakly (if at all) inhibited by caffeic acid, and are slightly more susceptible to ferulic than $p$-coumaric acid. Additional strains should be tested to confirm this trend. MIC for the different HCAs could not be used to reliably distinguish between $B$. anomalus and B. bruxellensis, nor was there a notable distinction for this trait between strains successfully used in commercial brewing and those unsuitable for beer fermentation.

Growth properties in the presence or absence of HCAs varied among most of the strains tested, but without clear distinctions between species or between brewing versus spoilage strains. For ten of twelve strains tested, there was no growth inhibition in $4 \mathrm{mM}$ caffeic acid compared to control cultures. This fits with the MIC data described above, where caffeic acid had the weakest inhibitory effect on all strains. Strains nine and twelve exhibited a slight but significant growth lag at $24 \mathrm{~h}$ when grown in caffeic acid, but no growth difference at remaining time points. Growth patterns for four strains $(2,3,7$ and 8$)$ were identical to the control cultures for all three HCAs. This was expected for strain eight, which had the highest MIC for all three HCAs, but is unexpected for strain three which was completely inhibited by $8 \mathrm{mM}$ ferulic acid and $10 \mathrm{mM}$-coumaric acid in the MIC analysis. All of the other strains showed a significant growth lag in both ferulic acid and $p$-coumaric acid. In all but two strains where a lag was observed, treated cultures recovered and matched control treated growth levels within $72 \mathrm{~h}$ of inoculation. Strain five was the most severely inhibited in growth and also exhibited the lowest MIC for ferulic and $p$-coumaric acids. Interestingly, strain twelve showed identical MIC data as strain five, but was only minimally inhibited for growth in $4 \mathrm{mM}$ HCAs. Strain 11 was inhibited similarly by both ferulic acid and $p$-coumaric acid, but not as severely as strain five.

Our growth data is broadly in line with work published by Harris, et al., [28] using different Dekkera isolates. Our strains were less growth inhibited at $4 \mathrm{mM}$ HCAs compared to the Dekkera isolates in $2 \mathrm{mM}$ HCAs. Several of the Dekkera isolates also exhibited a growth lag with $2 \mathrm{mM}$ caffeic acid, while our strains were consistently not inhibited by $4 \mathrm{mM}$ of this HCA. Edlin et al. [21] also analyzed growth of one strain B. anomalus in various HCAs, and observed relative inhibition similar to that described here.

Each strain's ability to metabolize various HCAs was assessed. As in the other assays, there was wide variation between strains, with one consistent feature: all of the strains metabolized caffeic least 
effectively. No other characteristic was consistent among all strains. Five of the 12 strains metabolized ferulic acid and $p$-coumaric acid to the same degree, and these two HCAs were metabolized between two-fold and three-fold more efficiently than caffeic acid. Of these five strains, three are B. bruxellensis and two are B. anomalus. All three B. bruxellensis strains were previously determined to produce organoleptic qualities inappropriate for brewing, and one of the $B$. anomalus strains fell into this category as well. The other $B$. anomalus strain has been used successfully in a brewery setting. Only strain seven metabolized $p$-coumaric acid more efficiently that ferulic acid. This is a $B$. anomalus strain suitable for brewing.

The remaining six strains all metabolized ferulic acid more efficiently than $p$-coumaric acid. The differences in use of these two HCAs varied widely among these strains, as did the overall level of metabolism. Within this "ferulic acid preference" group are members of both species, and all are able to generate organoleptic qualities suitable for brewing. This correlation is the most striking of the properties investigated for these 12 strains, and is highlighted in Table 3.

Many variables will determine the phenolic compound contribution to the organoleptic qualities of any particular finished beer or wine. The overall concentration and ratio of various HCAs is known to vary widely among different plant species (cereal grains and grapes included), and even between cultivars $[12,13]$. The proportion of each released into must or wort will vary based on the treatment of the raw materials before and during brewing and winemaking. These properties of raw materials are not generally a consideration when planning a fermentation, and in most cases the HCA values of particular grape harvests and maltings are not known. One exception is the inclusion of a ferulic acid rest to the mash protocol for certain beer styles when clove-like phenols are desired in the final product [29,30]. This $35^{\circ} \mathrm{C}$ rest activates feruloyl esterase, releasing ferulic acid from plant cell wall structures into the wort, where Pof + yeast strains will produce 4 -vinylguiacol during fermentation.

Here we investigated the potential of different species and strains of Brettanomyces yeast for variable contribution of phenolic compounds during fermentation. Recently, the full genome sequences of one brewing and three wine spoilage strains of Brettanomyces have become available [31-34]. A strain-by-strain sequence alignment of the PAD enzymes reveals a very high degree of amino acid sequence identity (Lentz, unpublished) [35]. Strains varied by zero, two or three amino acids out of 176 total. Interestingly, the highest similarity (100\% match across all 176 amino acids) was between one of the spoilage strains and the available Belgian brewery strain. Clearly, more enzyme sequences will be useful in determining the extent to which these small sequence differences contribute to variations in enzyme activity.

It is assumed that the undissociated form of the HCAs can diffuse at an appreciable rate through the plasma membrane into the cell where it is metabolized by the PAD enzyme [36]. Acetic acid can enter Saccharomyces cerevisiae yeast cells by this mechanism, but may also enter via large aquaporin channels [37]. There may be an uncharacterized channel or transporter that could add another layer of strain variability influencing phenolic acid metabolism in Brettanomyces yeast [38].

Strain variation is only one of several features that contribute to the phenolic character of beer or wine. There is wide variation in the absolute and relative quantities of HCAs in different grape musts and beer worts. This feature may contribute significantly to the observed differences in the contribution of Brettanomyces to beer versus wine. By controlling for this variable, our study helps to define the specific contribution of PAD enzyme activity to phenolic characteristics of beer and wine. 


\section{Conclusions}

We tested brewing and spoilage isolates of Brettanomyces yeast for growth inhibition and metabolism of hydroxycinnamic acids, constituents of both wine must and beer wort. There was wide variability for several of the properties tested, with little correlation to spoilage. We found that strains that metabolized ferulic acid more successfully that p-coumaric acid were all suitable for use in brewing. These results help to define one feature of Brettanomyces' contribution to the organoleptic qualities of beer and wine.

\section{Acknowledgments}

This work was partially supported by an AHA Research and Education Fund grant from the Brewers Association to M.L. Thanks to H. Grow and H. Daniel for data collection.

\section{Author Contributions}

M.L. conceived and designed the experiments; M.L. and C.H. performed the experiments and analyzed the data; M.L. wrote the paper.

\section{Conflicts of Interest}

The authors declare no conflict of interest.

\section{References}

1. Schifferdecker, A.J.; Dashko, S.; Ishchuk, O.P.; Piškur, J. The wine and beer yeast Dekkera bruxellensis. Yeast 2014, 31, 323-332.

2. Wedral, D.; Shewfelt, R.; Frank, J. The challenge of Brettanomyces in wine. LWT_Food Sci. Technol. 2010, 43, 1474-1479.

3. Zuehlke, J.M.; Petrova, B.; Edwards, C.G. Advances in the Control of Wine Spoilage by Zygosaccharomyces and Dekkera/Brettanomyces. Ann. Rev. Food Sci. Technol. 2013, 4, 57-78.

4. Suarez, R.; Suarez-Lepe, J.; Morata, A.; Calderon, F. The production of ethylphenols in wine by yeasts of the genera Brettanomyces and Dekkera: A review. Food Chem. 2007, 102, 10-21.

5. Garijo, P.; Gonzalez-Arenzana, L.; Lopez-Alfaro, I.; Garde-Cerda, T.; Lopez, R.; Santamaria, P.; Gutierrez, A.R. Analysis of grapes and the first stages of the vinification process in wine contamination with Brettanomyces bruxellensis. Eur. J. Food Res. Technol. 2015, 240, doi:10.1007/s00217-014-2351-4.

6. Loureiro, V.; Malfeito-Ferreira, M. Spoilage yeasts in the wine industry. Int. J. Food Microbiol. 2003, 86, 23-50.

7. Silva, P.; Cardoso, H.; Geros, H. Studies on the Wine Spoilage Capacity of Brettanomyces/Dekkera spp. Am. J. Enol. Vitic. 2004, 55, 65-72.

8. Chatonnet, P.; Dubourdieu, D.; Boidron, J.N.; Pons, M. The origin of ethylphenols in wines. J. Sci. Food Agric. 1992, 60, 165-178.

9. Heresztyn, T. Metabolism of volatile phenolic compounds from hydroxycinnamic acids by Brettanomyces yeast. Arch. Microbiol. 1986, 146, 96-98. 
10. Bidlack, J.; Malone, M.; Benson, R. Molecular Structure and Component Integration of Secondary Cell Walls in Plants. Proc. Okla Acad. Sci. 1992, 72, 51-56.

11. Faulds, C.B.; Williamson, G. The role of hydroxycinnamates in the plant cell wall. J. Sci. Food Agric. 1999, 79, 393-395.

12. Zhu, L.; Zhang, Y.; Lu, J. Phenolic contents and compositions in skins of red wine grape cultivars among various genetic backgrounds and originations. Int. J. Mol. Sci. 2012, 13, 3492-3510.

13. Yu, J.; Vasanthan, T.; Temelli, F. Analysis of phenolic acids in barley by high-performance liquid chromatography. J. Agric. Food Chem. 2001, 49, 4352-4358.

14. Pinelo, M.; Arnous, A.; Meyer, A.S. Upgrading of grape skins: Significance of plant cell-wall structural components and extraction techniques for phenol release. Trends Food Sci. Technol. 2006, 17, 579-590.

15. Vanbeneden, N.; Van Roey, T.; Willems, F.; Delvaux, F.; Delvaux, F.R. Release of phenolic flavour precursors during wort production: Influence of process parameters and grist composition on ferulic acid release. Food Chem. 2008, 111, 83-91.

16. Harris, V.; Jiranek, V.; Ford, C.; Grbin, P. Inhibitory effect of hydroxycinnamic acids on Dekkera spp. Appl. Microbiol. Biotechnol. 2010, 86, 721-729.

17. Stead, D. The effect of hydroxycinnamic acids and potassium sorbate on the growth of 11 strain of spoilage yeast. J. Appl. Bacteriol. 1995, 78, 82-87.

18. Pastorkova, E.; Zakova, T.; Landa, P.; Novakova, J.; Vadlejch, J.; Kokoska, L. Growth inhibitory effect of grape phenolics against wine spoilage yeasts and acetic acid bacteria. Int. J. Food Microbiol. 2013, 161, 209-213.

19. Rosazza, J.P.N.; Huang, Z.; Dostal, L.; Volm, T.; Rousseau, B. Review: Biocatalytic transformations of ferulic acid: An abundant aromatic natural product. J. Ind. Microbiol. 1995, 15, 457-471.

20. Shinohara, T.; Kubodera, S.; Yanagida, F. Distribution of phenolic yeasts and production of phenolic off-flavors in wine fermentation. J. Biosci. Bioeng. 2000, 90, 90-97.

21. Edlin, D.A.N.; Narbad, A.; Dickinson, J.R.; Lloyd, D. The biotransformation of simple phenolic compounds by Brettanomyces anomalus. FEMS Microbiol. Lett. 1995, 125, 311-316.

22. Weaver, K. Report: The Fastest Growing Beer Styles, on RateBeer. Available online: http://us2.campaign-archive1.com/?u=927a170c4a7bc5ac2c11d7a5f\&id=ae8ff00c56 (accessed on 6 May 2015).

23. Curtin, C.D.; Pretorius, I.S. Genomic insights into the evolution of industrial yeast species Brettanomyces bruxellensis. FEMS Yeast Res. 2014, 14, 997-1005.

24. Daenen, L.; Saison, D.; Sterckx, F.; Delvaux, F.R.; Verachtert, H.; Derdelinckx, G. Screening and evaluation of the glucoside hydrolase activity in Saccharomyces and Brettanomyces brewing yeasts. J. Appl. Microbiol. 2008, 104, 478-488.

25. Vanbeneden, N.; Gils, F.; Delvaux, F.; Delvaux, F.R. Formation of 4-vinyl and 4-ethyl derivatives from hydroxycinnamic acids: Occurrence of volatile phenolic flavour compounds in beer and distribution of Pad1-activity among brewing yeasts. Food Chem. 2008, 107, 221-230.

26. Lentz, M.; Putzke, T.; Hessler, R.; Luman, E. Genetic and physiological characterization of yeast isolated from ripe fruit and analysis of fermentation and brewing potential. J. Inst. Brew. 2014, 120, 559-564. 
27. Harris, V.; Ford, C.; Jiranek, V.; Grbin, P. Survey of enzyme activity responsible for phenolic off-flavour production by Dekkera and Brettanomyces yeast. Appl. Microbiol. Biotechnol. 2009, 81, 1117-1127.

28. Harris, V.; Ford, C.; Jiranek, V.; Grbin, P. Dekkera and Brettanomyces growth and utilisation of hydroxycinnamic acids in synthetic media. Appl. Microbiol. Biotechnol. 2008, 78, 997-1006.

29. Humberstone, F.J.; Briggs, D.E. Extraction and assay of ferulic acid esterase from malted barley. J. Inst. Brew. 2000, 106, 21-29.

30. Szwajgier, D.; Wasko, A.; Targonski, Z. Influence of $\mathrm{pH}$ and temperature on ferulic acid esterase and acetic acid esterase activities during malting and mashing. Pol. J. Food Nutr. Sci. 2006, 15, 183-191.

31. Borneman, A.R.; Zeppel, R.; Chambers, P.J.; Curtin, C.D. Insights into the Dekkera bruxellensis genomic landscape: comparative genomics reveals variations in ploidy and nutrient utilisation potential amongst wine isolates. PLoS Genet. 2014, 10, e1004161.

32. Curtin, C.D.; Borneman, A.R.; Chambers, P.J.; Pretorius, I.S. De-novo assembly and analysis of the heterozygous triploid genome of the wine spoilage yeast Dekkera bruxellensis AWRI1499. PLOS ONE 2012, 7, e33840.

33. Piskur, J.; Ling, Z.; Marcet-Houben, M.; Ishchuk, O.; Aerts, A.; LaButti, K.; Copeland, A.; Lindquist, E.; Barry, K.; Compagno, C.; et al. The genome of wine yeast Dekkera bruxellensis provides a tool to explore its food-related properties. Int. J. Food Microbiol. 2012, 157, 202-209.

34. Woolfit, M.; Rozpedowska, E.; Piskur, J.; Wolfe, K.H. Genome survey sequencing of the wine spoilage yeast Dekkera (Brettanomyces) bruxellensis. Eukaryot. Cell 2007, 6, 721-733.

35. Lentz, M. University of North Florida, Jacksonville, FL, USA. Unpublished work, 2015.

36. Campolongo, S.; Siegumfeldt, H.; Aabo, T.; Cocolin, L.; Arneborg, N. The effects of extracellular $\mathrm{pH}$ and hydroxycinnamic acids influence the intracellular $\mathrm{pH}$ of Brettanomyces bruxellensis DSM 7001. LWT Food Sci. Technol. 2014, 59, 1088-1092.

37. Brul, S.; Coote, P. Preservative agents in foods: Mode of action and microbial resistance mechanisms. Int. J. Food Microbiol. 1999, 50, 1-17.

38. Casal, M.; Paiva, S.; Queiros, O.; Soares-Silva, I. Transport of carboxylic acids in yeast. FEMS Microbiol. Rev. 2008, 32, 974-994.

(C) 2015 by the authors; licensee MDPI, Basel, Switzerland. This article is an open access article distributed under the terms and conditions of the Creative Commons Attribution license (http://creativecommons.org/licenses/by/4.0/). 